\title{
C-reactive protein correlates with tissue oxygen availability in patients with stable COPD
}

\author{
Simonetta Baldi' \\ Gian Domenico Pinna' \\ Piera Mombaruzzo' \\ Milena Biglieri' \\ Angelo De Martini' \\ Paolo Palange ${ }^{2}$ \\ 'Department of Pneumology \\ and Biomedical Engineering, Scientific \\ Institute of Montescano, Salvatore \\ Maugeri Foundation IRCCS, Pavia, \\ Italy; ${ }^{2}$ Respiratory Pathophysiology \\ Unit, Clinical Medicine Department, \\ "La Sapienza" University, Rome, \\ Italy
}

\begin{abstract}
Background: Arterial oxygen tension, oxygen delivery to tissue, and systemic inflammation are recognized as pivotal factors in the progression of chronic obstructive pulmonary disease (COPD). However, interconnections between systemic inflammation and tissue oxygen availability are scantly investigated. Tissue oxygen availability depends on arterial $\mathrm{PaO}_{2}$, oxygen concentration, hemoglobin oxygen affinity $\left(\mathrm{P}_{50}\right)$, and hemoglobin oxygen binding capacity $(\mathrm{cHb})$. As the integrated changes of those indices are summarized by oxygen extraction tension $\left(\mathrm{PaO}_{2 \mathrm{x}}\right)$, the objective of this study was to explore the association between C-reactive protein (CRP) blood levels and either $\mathrm{PaO}_{2 \mathrm{x}}$ or each of its determinants, in stable COPD.
\end{abstract}

Materials and methods: Blood CRP and oxygen status of arterial blood were measured at rest while breathing room air in 44 moderate to severe stable COPD patients. $\mathrm{PaO}_{2 \mathrm{x}}$ was calculated along the shape of oxygen binding curve as the oxygen tension resulting from removal of $2.3 \mathrm{mmol}$ of oxygen per liter of blood. Multiple linear regression analysis was performed with $\mathrm{PaO}_{2}, c \mathrm{eHb}$, and $\mathrm{P}_{50}$ as independent variables, and $\mathrm{CRP}$ as the dependent variable, adjusting for age and sex. The analysis was repeated using $\mathrm{PaO}_{2 \mathrm{x}}$ as a sole independent variable.

Results: Multiple linear regression analysis indicated that ceHb, $\mathrm{PaO}_{2}$, and $\mathrm{P}_{50}$, were significant and independent predictors of $\mathrm{CRP}\left(\mathrm{R}^{2}=0.52, \mathrm{p}<0.0001\right) . \mathrm{PaO}_{2 \mathrm{x}}$ alone was an even stronger predictor of CRP $\left(\mathrm{R}^{2}=0.62, \mathrm{p}<0.0001\right)$.

Conclusions: These findings indicate that physiological determinants of tissue oxygen availability are independently associated with CRP blood levels. Thus, improvement of tissue oxygen availability is a central therapeutic option to modulate the severity of systemic inflammatory processes in patients with COPD.

Keywords: COPD, C-reactive protein, oxygen extractivity, systemic inflammation

\section{Introduction}

Systemic inflammation (Agustí et al 2003) together with arterial hypoxemia and oxygen delivery to tissue (Kawakami et al 1983) are known to influence the prognosis of chronic obstructive pulmonary disease (COPD). Nevertheless, whether systemic inflammatory process is primarily linked to the convective/diffusive process of oxygen transport from the lung to tissues or it is just a secondary phenomenon has not been well acknowledged yet, as the origin of systemic inflammation remains poorly understood in patients with COPD (Wouters 2005).

Recently published papers have reported that increased C-reactive protein (CRP) blood levels mark the metabolic and functional impairment in patients with stable COPD (Schols et al 1996; de Torres et al 2006; Broekhuizen et al 2006; Pinto-Plata et al 2006). Previous studies have also documented that wasting syndrome occurs in COPD patients with elevated arteriovenous oxygen difference, as a result of low arterial and mixed venous oxygenation (Filley et al 1968; Kawakami et al 1983). However, Broekhuizen and colleagues (2006) found no difference in arterial oxygen tension $\left(\mathrm{PaO}_{2}\right)$ between patients with normal and raised CRP levels, while de Torres 
and colleagues (2006) found that no more than $20 \%$ of the variability of CRP is accounted for by $\mathrm{PaO}_{2}$.

It is well acknowledged that hypoxia induces the synthesis of inflammatory cytokines and the expression of adhesion molecules in different cell types and tissues in vitro (Ghezzi et al 1991), as well as in humans exposed at high altitude (Hartmann et al 2000). We wondered whether the severity of systemic inflammation, as assessed by CRP blood levels, is instead associated with tissue hypoxia rather than with arterial hypoxemia alone in patients with COPD. To test this hypothesis, we explored the relationship between systemic inflammation, as assessed by CRP blood levels, and each single determinant of oxygen status of arterial blood, ie, $\mathrm{PaO}_{2}$, blood oxygen carrying capacity, and blood oxygen affinity. We also explored the relationship between CRP blood levels, and oxygen extraction tension $\left(\mathrm{PaO}_{2 \mathrm{x}}\right)$, as this is a noninvasive measurement of peripheral oxygen availability, which summarizes the degree of compensation among arterial oxygen tension, blood oxygen carrying capacity and affinity (Siggard-Andersen et al 1995) and reflects changes of cardiac output, which may affect extraction ratio and mixed venous oxygen tension (Ringsted et al 1990).

\section{Methods}

All COPD patients, consecutively referred to our in-patients pulmonary rehabilitation center of Montescano, Italy from January 2004 to January 2006, were considered eligible for the present study. They had to meet the American Thoracic Society (ATS) criteria for diagnosis of COPD (Pauwels et al 2001). Patients were excluded if they had: 1) idiophatic or acquired bronchiectasis; 2) COPD exacerbations within the last 4 weeks; 3 ) diagnosed cardiovascular disease (coronary artery, peripheral vascular, or cerebrovascular disease); 4) systemic confounding inflammatory disease, such as rheumatoid arthritis, psoriatic arthritis, systemic vasculitis, polymyalgia rheumatica, Crohn's disease, or allergic complication of infections: eg, erythema nodosum, rheumatic fever; 5) malignancies.

Patients had to be clinically stable at the time of examination (no exacerbation within the last 4 weeks) on a standard treatment regimen consisting of inhaled corticosteroids, and beta adrenergic, and/or anticholinergic drugs. None of the patients had to be on systemic corticosteroids. The presence of cardiovascular risk factors (hypertension, diabetes, hypercholesterolemia) was registered. It was also noted whether patients were currently smoking, and whether they were on long-term oxygen therapy (LTOT). The Medical
Ethics Committee at our institution approved the study design and a written informed consent was obtained prior to the study.

Forced expiratory volume in one second $\left(\mathrm{FEV}_{1}\right)$, forced vital capacity (FVC), inspiratory forced vital capacity (IVC), and total lung capacity (TLC) were determined using a Jaeger spirometer and body box (Masterlab, Jaeger, Würzburg, Germany). $\mathrm{FEV}_{1}$ was also measured 15 minutes after four inhalations of salbutamol $(400 \mu \mathrm{g})$ from a metered-dose inhaler. Predicted equations utilized were those of Quanjer and colleagues (1993). Carbon monoxide transfer factor $\left(\mathrm{TL}_{\mathrm{CO}}\right)$ was measured (Baires System, Biomedin, Padua, Italy) using the single breath method and according to the ATS recommendation (ATS 1995). Reference equations utilized were those of Cotes (1979).

Functional status of the patients was assessed by BODE (body mass index, degree of airflow obstruction, dyspnea, and exercise capacity) index (Celli et al 2004). This is a multidimensional grading system based on: 1) the measurement of body mass index (BMI, $\left.\mathrm{Kg} / \mathrm{m}^{2}\right)$; 2) $\mathrm{FEV}_{1}, \%$ predicted; 3) degree of dyspnea, measured with the modified Medical Research Council (MMRC) dyspnea scale; and 4) the evaluation of exercise tolerance, as reflected by the distance walked at the 6 minute walking test (6MWD).

Fasting EDTA blood samples were collected, early in the morning (8:00-10:00 hours). CRP was measured in duplicate by high sensitivity turbidimetric immuno-assay (PETIA) (Dade Behring) with a lower detection limit of $0.5 \mathrm{mg} / \mathrm{L}$.

Arterial blood samples were gently drawn from the brachial artery using a dedicated preheparinized blood sampler, while patients were seated and breathing room air. Oxygen breathing was temporarily withdrawn for at least 30 minutes in patients under oxygen therapy. Immediately after sample collection, mixing, and removal of the first drops of blood, the acid-base and oxygen status were analyzed. Arterial negative logarithm of hydrogen ion concentration $(\mathrm{pH})$ and arterial carbon dioxide tensions $\left(\mathrm{PaCO}_{2}\right)$, together with arterial oxygen tension $\left(\mathrm{PaO}_{2}\right)$ and the oximetry parameters were measured using a blood gas analyzer (ABL Model 700 System Radiometer, Copenhagen, Denmark). The following oximetry parameters were directly measured: 1) concentration of total hemoglobin in the blood (tHb), which includes all types of hemoglobin ie, oxy- $\left(\mathrm{O}_{2} \mathrm{Hb}\right)$, deoxy- $(\mathrm{HHb})$, carboxy- $(\mathrm{COHb})$, and meta-hemoglobin (MetHb); 2) arterial oxygen saturation 
$\left(\mathrm{sO}_{2}\right)$ (ie, the ratio between the concentration of $\mathrm{O}_{2} \mathrm{Hb}$ and $\left.\mathrm{HHb}+\mathrm{O}_{2} \mathrm{Hb}\right) ; 3$ ) fraction of oxyhemoglobin $\left(\mathrm{FO}_{2} \mathrm{Hb}\right)$ (ie, the ratio between the concentration of $\mathrm{O}_{2} \mathrm{Hb}$ and $\mathrm{tHb}$ ); 4) fraction of carboxyhemoglobin $(\mathrm{FCOHb})$ (ie, the ratio between concentration of $\mathrm{COHb}$ and $\mathrm{tHb}) ; 5$ ) fraction of metahemoglobin (FMetHb) (ie, the ratio between concentration of $\mathrm{MetHb}$ and $\mathrm{tHb})$; 6) total arterial oxygen content $\left(\mathrm{ct} \mathrm{O}_{2}\right.$ ) (ie, the sum of the concentration of hemoglobin-bound oxygen and the concentration of physically dissolved oxygen). The concentration of effective hemoglobin $(c \mathrm{eHb})$ ie, the concentration of total hemoglobin $(c \mathrm{tHb})$ corrected for fractions of carboxyhemoglobin $(\mathrm{FCOHb})$ and metahemoglobin $(\mathrm{FMetHb})$, which are unable to bind oxygen reversibly was calculated as a measurement of hemoglobin oxygen binding capacity. Both oxygen tension at half saturation $(50 \%)$ of blood $\left(\mathrm{P}_{50}\right)$, and oxygen extraction tension of arterial blood $\left(\mathrm{PaO}_{2 \mathrm{x}}\right)$, were calculated by extrapolation along the shape of the oxygen binding curve on the $\log \mathrm{PaO}_{2}-\mathrm{ctO}_{2}$ diagram, by a dedicated computer program (Siggard-Andersen and SiggardAndersen 1990). The shape of the curve was modeled on the basis of the $\mathrm{PaO}_{2}$ and the hemoglobin oxygen saturation fraction meas ured in the arterial blood, using a hyperbolic tangent function (Siggaard-Andersen et al 1984).

\section{Statistical analysis}

The relationship between CRP and the determinants of oxygen extractivity $\left(\mathrm{PaO}_{2}, \mathrm{ceHb}\right.$, and $\left.\mathrm{P}_{50}\right)$ was assessed by multiple linear regression analysis, adjusting for age and sex. The same analysis was carried out to assess the relationship between CRP and $\mathrm{PaO}_{2 \mathrm{x}}$, the latter being considered as a comprehensive index of oxygen availability. Descriptive statistics are expressed as mean, standard deviation (SD) or median and interquartile range (IQR). A p value $<0.05$ was considered statistically significant.

\section{Results}

A hundred and fifty-four patients with COPD were assessed for eligibility, and 101 of them were excluded from the analysis because they had either concurrent inflammatory disease or diagnosed cardiovascular disease that may raise CRP blood levels. The reasons and the numbers of excluded patients are detailed in Figure 1. Nine of the patients refused to participate in the study, therefore 44 COPD patients ( 34 men and 10 women) were recruited in the study. Anthropometric and functional characteristics are reported in Table 1 . Most of the patients (41\%) were in GOLD stage IV, 93\% were exsmokers, and 1rrent smokers, with a smoking history of $61 \pm 31$ (mean \pm SD) pack-years.

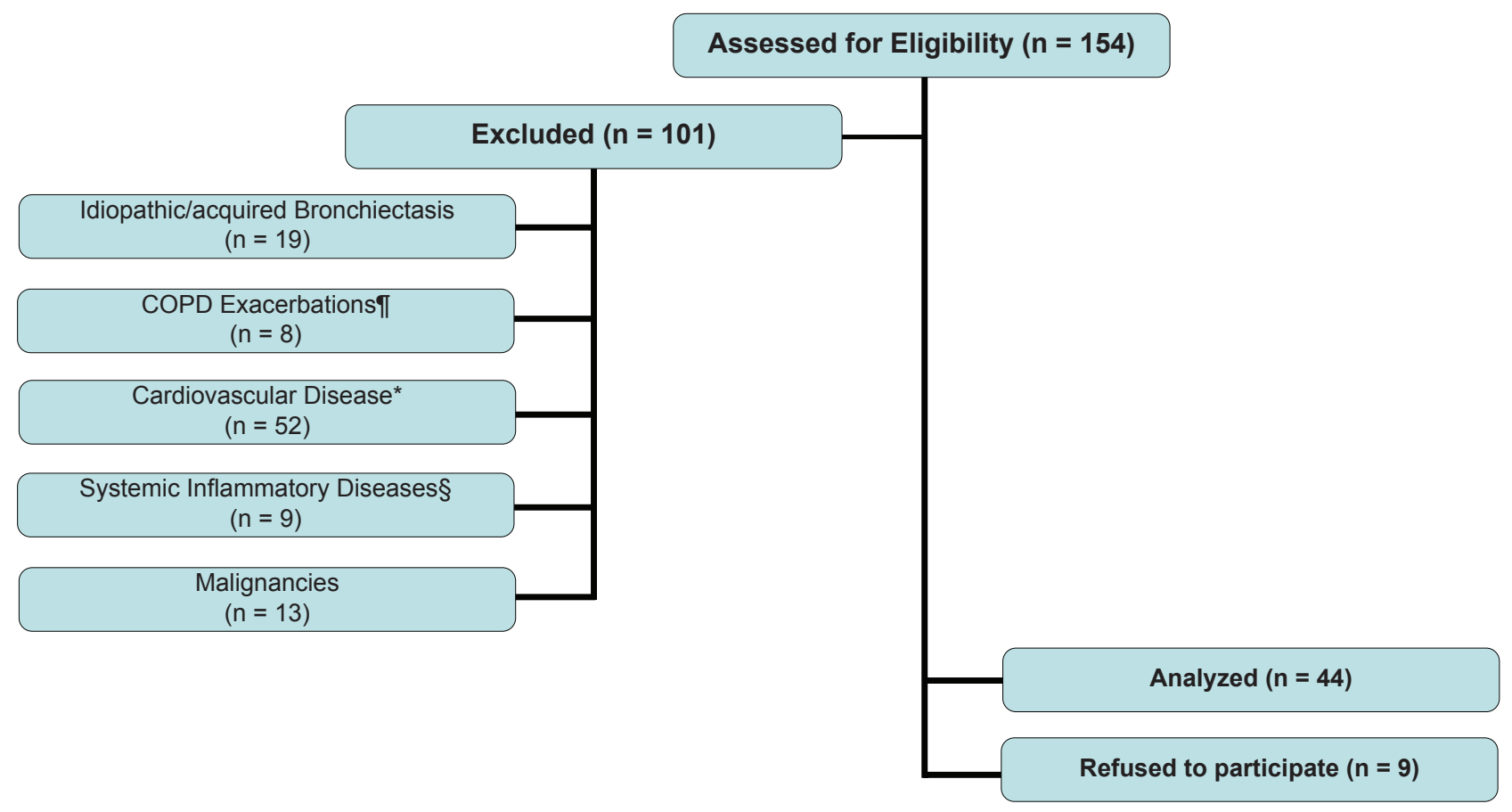

Figure I Flow of eligible COPD participants through the analysis.

Notes: Exclusion criteria: "COPD exacerbations within the last 4 weeks; *Diagnosed cardiovascular disease (coronary artery, peripheral vascular, or cerebrovascular disease); §Systemic inflammatory disease, such as rheumatoid arthritis, psoriatic arthritis, systemic vasculitis, polymyalgia rheumatica, Crohn's disease, or allergic complication of infections: eg, erythema nodosum, rheumatic fever, etc. 
Cardiovascular risk factors were present in $64 \%$ of the patients. Out of $44,43 \%$ of patients was on LTOT. The majority of patients $(96 \%)$ was on inhaled corticosteroid therapy, none of them assumed systemic steroids at the time of the study; $61 \%$ was on antihypertensive drugs; $7 \%$ of patients was on statins.

The performance status as assessed by BODE index was scored $\geq 8$ in $16 \%$ of patients, indicating a severely impaired performance. The median interquartile range CRP $\mathrm{mg} / \mathrm{L}$ was 4.3 (3.0-8.4).

Multiple linear regression analysis indicates that $c \mathrm{eHb}$, $\mathrm{PaO}_{2}$, and $\mathrm{P}_{50}$ were independently and significantly associated with blood CRP, $\left(\mathrm{R}^{2}=0.52, \mathrm{p}<0.0001\right)$. In Table 2 , beta coefficients, standard errors, $t$ values and $\mathrm{p}$ values are reported. An even stronger association was found when $\mathrm{ceHb}$, $\mathrm{PaO}_{2}$, and $\mathrm{P}_{50}$ were replaced by $\mathrm{PaO}_{2 \mathrm{x}}\left(\mathrm{R}^{2}=0.62, \mathrm{p}<0.0001\right)$, see Table 3. The specific contribution of $\mathrm{PaO}_{2 \mathrm{x}}$ to $\mathrm{CRP}$ variability was $56 \%$.

\section{Discussion}

C-reactive protein is recognized as a biomarker of the systemic inflammatory response that characterizes patients with COPD (Agustí et al 2003; Schols et al 1996; Gan

Table I Clinical and physiologic characteristics of 44 patients with stable COPD

\begin{tabular}{llll}
\hline & Mean & (SD) & Range \\
\hline Age, year & 68.7 & 8.6 & $49-83$ \\
$\mathrm{BMI}, \mathrm{Kg} / \mathrm{m}^{2}$ & 26.4 & 4.3 & $18-35$ \\
$\mathrm{FEV}_{1}, \%$ predicted & 47.9 & 20.9 & $12-76$ \\
MMRC-D, point & 2.7 & 1.0 & $\mathrm{I}-4$ \\
6MWD m & 298 & $1 \mathrm{I} 2$ & $80-500$ \\
$\mathrm{BODE}$, points & 4.6 & 2.7 & $2-10$ \\
$\mathrm{TL}_{\mathrm{co}} \%$ predicted & 49.3 & 22.4 & $6-75$ \\
$\mathrm{tHb}, \mathrm{g} / \mathrm{dl}$ & 14.2 & 1.8 & $10-17$ \\
$\mathrm{FCOHb} \%$ & 2.3 & 0.8 & $1.6-5.4$ \\
$\mathrm{FMetHb}^{2} \%$ & 0.6 & 0.3 & $0.6-1.0$ \\
$\mathrm{FO}_{2} \mathrm{Hb}, \%$ & 90.6 & 3.7 & $83-95$ \\
$\mathrm{sO}_{2}, \%$ & 92.8 & 3.8 & $85-96$ \\
$\mathrm{PaCO}_{2}, \mathrm{mmHg}$ & 40.5 & 6.7 & $27-53$ \\
$\mathrm{PaO}_{2}, \mathrm{mmHg}$ & 63.8 & 10.4 & $42-86$ \\
$\mathrm{PaO}_{2 \times}, \mathrm{mmHg}$ & 30.2 & 2.3 & $24-33$ \\
$\mathrm{P}_{50}, \mathrm{mmHg}$ & 23.2 & 1.9 & $18-26$ \\
\hline
\end{tabular}

Abbreviations: BMI, body mass index; BODE, BMI, degree of airflow obstruction, dyspnea, and exercise capacity index; COPD, chronic obstructive pulmonary disease; $\mathrm{FEV}_{1}$, forced expiratory volume in one second; $\mathrm{FCOHb}$, fraction of carboxyhemoglobin; FMetHb, fraction of metahemoglobin; $\mathrm{FO}_{2} \mathrm{Hb}$, fraction of oxyhemoglobin; MMRC-D, scores on the Modified Medical Research Council dyspnea scale; $\mathrm{PaCO}_{2}$, arterial carbon dioxide tensions; $\mathrm{PaO}_{2}$, arterial oxygen tension; $\mathrm{PaO}_{2 x}$, oxygen extraction tension; $\mathrm{P}_{50}$, oxygen half saturation tension; $\mathrm{sO}_{2}$, arterial oxygen saturation; tHb, total hemoglobin; 6MWD, distance walked in six minutes. et al 2004). The results of our study confirm previous data (Broekhuizen et al 2006; Schols et al 1996; Pinto-Plata et al 2006) that CRP levels are increased in stable COPD patients, and provide the novel finding of a strong association between reduced "oxygen extractivity" and CRP blood level in stable disease condition.

The term "oxygen extractivity" originally proposed by Siggaard-Andersen and colleagues (1995) indicates the property which allows tissues to extract the usual amount of oxygen without a fall in oxygen tension below the usual venous level. This is measured along the shape of the oxygen binding curve, and quantified as oxygen extraction tension $\left(\mathrm{PaO}_{2 \mathrm{x}}\right.$ ) (Siggaard-Andersen et al 1984). $\mathrm{PaO}_{2 \mathrm{x}}$ describes disturbances in oxygen availability depending on arterial oxygen tension, hemoglobin oxygen affinity and hemoglobin oxygen binding capacity, and reflects adjustments of cardiac output to maintain normal venous oxygen tension, if oxygen consumption is normal (Ringsted et al 1990). Thus, we take $\mathrm{PaO}_{2 \mathrm{x}}$ as a convenient estimation of the bio-energetic process of the convective/diffusive oxygen transport from the lung to tissues (Siggard-Andersen et al 1995).

The finding of a strong association between CRP and $\mathrm{PaO}_{2 \mathrm{x}}$, as assessed by the Siggaard-Andersen's algorithm (Siggard-Andersen and Siggard-Andersen 1990), suggests a pathogenic link between systemic inflammation and reduced oxygen extractivity at tissue level. This result is also supported by the finding of a significant and independent predictive value of $\mathrm{PaO}_{2}$ after adjustment for $c \mathrm{eHb}, \mathrm{P}_{50}$, age, and sex.

These data are not in contrast with those of de Torres and colleagues (2006), who report that CRP blood levels best correlate with $\mathrm{PaO}_{2}$ in 130 stable COPD patients. Furthermore, dependence of $\mathrm{PaO}_{2 \mathrm{x}}$ on hemoglobin oxygen affinity, hemoglobin oxygen capacity, and $\mathrm{PaO}_{2}$ forwards the idea that oxygenation state of hemoglobin, and total number of hemoglobin molecules play a regulatory role on peripheral oxygen availability, together with arterial hypoxemia.

Previous studies (Filley et al 1968; Burrows et al 1972) indicated that COPD patients with a low cardiac output pattern have more problems with tissue oxygenation during exercise than is apparent from their arterial hypoxemia at rest, and that tissue hypoxia may account at least in part for muscle weakness and impaired performance during physical activity. This issue has been further addressed by Schols et al (Schols et al 1996) who suggested the notion of a link between CRP and impaired exercise capacity and distress due to respiratory symptoms. Moreover, González-Alonso 
Table 2 Multiple linear regression analysis with CRP as the dependent variable

\begin{tabular}{lllll}
\hline Independent variable & Beta coefficient & Standard error & T value & P value \\
\hline $\mathrm{ceHb}, \mathrm{g} / \mathrm{dl}$ & -0.063 & 0.027 & -2.32 & 0.025 \\
$\mathrm{PaO}_{2}, \mathrm{mmHg}$ & -0.028 & 0.006 & -4.59 & $<0.000 \mathrm{I}$ \\
$\mathrm{P}_{50}, \mathrm{mmHg}$ & -0.150 & 0.033 & -4.50 & $<0.000 \mathrm{I}$ \\
$\mathrm{Sex}, \mathrm{M} / \mathrm{F}$ & -0.098 & 0.127 & -0.77 & 0.45 \\
Age, $\mathrm{yr}$ & -0.015 & 0.005 & -2.67 & 0.011 \\
Intercept & 8.006 & 1.241 & 6.45 & $<0.0001$ \\
\hline
\end{tabular}

Note: $\mathrm{R}^{2}=0.52$.

Abbreviations: ceHb, hemoglobin oxygen binding capacity; $\mathrm{CRP}, \mathrm{C}$-reactive protein; $\mathrm{PaO}_{2}$, arterial oxygen tension; $\mathrm{P}_{50}$, oxygen half saturation tension.

and colleagues (2006) reported that local regulation of skeletal muscle blood flow and $\mathrm{O}_{2}$ delivery primarily senses alterations in the oxygenation state of hemoglobin, suggesting an important role of blood $\mathrm{O}_{2}$ gradients in muscle microcirculatory control. Our findings further emphasize these concepts. They deserve further attention to unravel molecular responses elicited by tissue hypoxia within the lung, the systemic circulation, and the muscles, such as the hypothesized metabolic uncoupling between the citric acid cycle and the electron transport chain at mitochondria level in patients with COPD and chronic respiratory failure (Chance et al 1986; Sauleda et al 1998).

Recent studies (Kishimoto et al 1989; Jakobsson 1990; Maltais et al 1996; Yu et al 1998; Semenza 2000; Takabatake et al 2000; Engelen et al 2000; Keller et al 2001) have begun to delineate pathophysiology of hypoxic chronic lung diseases in terms of changes in gene expression that are mediated by transcription factors like HIF 1, tumor necrosis factor system and nuclear factor interleukin (IL)6, among the others. As the pro-inflammatory cytokine IL-6 largely regulates plasma concentrations of CRP, the molecular mechanisms that link CRP blood levels and tissue hypoxia seem to be a crucial point for a better understanding of the origin of systemic inflammatory process in COPD.

Haagobian and colleagues (2006) documented the association between IL- 6 mediated increase of CRP and either hypoxia, or exercise, or caloric deficit in normal subjects, who exercise at high altitude. Furthermore, in healthy subjects exposed at high altitude, a moderate increase of CRP levels is reported to follow the upregulation of both cytokine IL-6 and interleukin-1 receptor antagonist (IL-1 ra), arguing for the onset of a low-grade acute phase response to an inflammatory stimulus such as hypoxia at high altitude (Hartmann et al 2000). Similarly, in our COPD patients the reported increase of rest blood CRP levels below the range expected for acute inflammation invites speculation on a low-grade chronic IL-6 release in response to chronic hypoxia. The decreased CRP levels and IL-6 and spontaneous production of IL-6 by monocytes by n-CPAP in patients with obstructive sleep apnea syndrome (OSAS) might provide another evidence supporting this idea in relation to intermittent hypoxia (Yokoe et al 2003).

The exclusion from the analysis of about $2 / 3$ of the patients with COPD according to the criteria detailed in Figure 1 could be regarded as a potential limitation of the study. However, out of 101 patients excluded from the analysis, 52 had a diagnosed cardiovascular disease. Therefore, the percentage of COPD patients showing the presence of cardiovascular risk factors or diseases (52\%) does not differ from previously published data (de Torres et al 2006). Thus, we are confident that the patients included in the analysis were also representative of the general COPD population.

Table 3 Multiple linear regression analysis with CRP as the dependent variable

\begin{tabular}{lllll}
\hline Independent variable & Beta coefficient & Standard error & T value & P value \\
\hline $\mathrm{PaO} 2 \mathrm{x}, \mathrm{mmHg}$ & -0.139 & 0.020 & -6.91 & $<0.0001$ \\
$\mathrm{Sex}, \mathrm{M} / \mathrm{F}$ & -0.089 & 0.106 & -0.84 & 0.41 \\
$\mathrm{Age}, \mathrm{yr}$ & -0.010 & 0.005 & -1.98 & 0.054 \\
Intercept & 5.621 & 0.643 & 8.73 & $<0.000 \mathrm{I}$ \\
\hline
\end{tabular}

Note: $R^{2}=0.62$.

Abbreviations: $\mathrm{CRP}, \mathrm{C}$-reactive protein; $\mathrm{PaO}_{2 \mathrm{x}}$, oxygen extraction tension. 


\section{Conclusion}

Our findings clearly indicate that systemic inflammation is strongly related to reduced oxygen extractivity, and presumably tissue hypoxia, throughout the interplay of either intrapulmonary oxygen transport and blood supply mechanisms, or systemic regulatory aspects of hemoglobin oxygen transport. Our data allow some speculation on how the responses to chronic exposure to low oxygen concentrations have evolved into adaptive mechanisms operating at tissue level. To the extent that under conditions of tissue hypoxia these responses also promote a systemic damage, COPD would become a key element boosting other systemic inflammatory processes. As a practical implication, the improvement of tissue oxygen availability becomes a central therapeutic option to modulate the severity of systemic inflammatory process in patients with COPD.

\section{Acknowledgments}

The authors thank the Respiratory Pathopsychology laboratory staff of Montescano Rehabilitation institute for technical assistance; Mrs. Alma Chiapponi for secretarial assistance, and Mrs. Jennifer Chesterfield for English editing assistance. The authors report no conflicts of interest in this work.

\section{References}

Agustí AGN, Noguera A, Sauleda J, et al. 2003. Systemic effects of chronic obstructive pulmonary disease. Eur Respir J, 21:347-60.

[ATS] American Thoracic Society. 1995. Single-breath carbon monoxide diffusing capacity (transfer factor). Recommendations for a standard technique-1995 update. Am J Respir Crit Care Med, 152:2185-98.

Broekhuizen R, Wouters EFM, Creutzberg EC, et al. 2006. Raised CRP levels mark metabolic and functional impairment in advanced COPD. Thorax, 61:17-22.

Burrows B, Kettel LJ, Niden AH, et al. 1972. Patterns of cardiovascular dysfunction in chronic obstructive lung disease. $N$ Engl $J$ Med, 27:912-8.

Celli BR, Cote CG, Marin JM, et al. 2004. The body-mass index, airflow obstruction, dyspnea, and exercise capacity index in chronic obstructive pulmonary disease. $N$ Engl J Med, 350:1005-12.

Chance B, Leigh JS, Kent J, et al. 1986. Multiple controls of oxidative metabolism in living tissue as studied by phosphorus magnetic resonance. Proc Natl Acad Sci U S A, 83:9458-62.

Cotes JE. 1979. Lung function: assessment and application in medicine. 4th ed. Oxford: Blackwell Scientific Publications.

de Torres JP, Cordoba-Lanus E, López-Aguilar C, et al. 2006. C-Reactive protein levels and clinically important predictive outcomes in stable COPD patients. Eur Respir J, 27:902-7.

Engelen MP, Schols AM, Does JD, et al. 2000. Exercise-induced lactate increase in relation to muscles substrates in patients with chronic obstructive pulmonary disease. Am J Respir Crit Care Med, 162:1697-704.

Filley GF, Beckwitt HJ, Reeves JT, et al. 1968. Chronic obstructive bronchopulmonary disease. II. Oxygen transport in the two clinical types. Am J Med, 44:26-38.

Gan WQ, Man SFP, Senthilselvan A, et al. 2004. Association between chronic obstructive pulmonary disease and systemic inflammation: a systematic review and meta-analysis. Thorax, 59:574-80.
Ghezzi P, Dinarello CA, Bianchi M, et al. 1991. Hypoxia increases production of interleukin-1 and tumor necrosis factor by human mononuclear cells. Cytokine, 3:189-94.

Gonzalez-Alonso J, Mortensen S, Dawson EA, et al. 2006. Erythrocytes and the regulation of human skeletal muscle blood flow and oxygen delivery: role of erythrocyte count and oxygenation state of hemoglobin. J Physiol, 572:295-305.

Hagobian TA, Jacobs KA, Subudhi AW, et al. 2006. Cytokine response at high altitude: effects of exercise and antioxidants at $4300 \mathrm{~m}$. Med Sci Sports Exerc, 38:276-85.

Hartmann G, Tschöp M, Fischer R, et al. 2000. High altitude increases circulating Interleukin-6, Interleukin-1 receptor antagonist and C-reactive protein. Cytokine, 12:246-52.

Jakobsson P, Jarfeld L, Brundin A. 1990. Skeletal muscles metabolites and fiber types in patients with advanced chronic obstructive pulmonary disease. Eur Respir J, 3:192-6.

Kawakami Y, Kishi F, Yamamoto H, et al. 1983. Relation of oxygen delivery, mixed venous oxygenation, and pulmonary hemodynamics to prognosis in chronic obstructive pulmonary disease. $N$ Engl J Med, 308:1405-7.

Keller C, Steenberg A, Pilegaard H, et al. 2001. Transcriptional activation of the IL-6 gene in human contracting skeletal muscle: influence of muscle glycogen content. FASEB $J, 15: 2748-50$.

Kishimoto T. 1989. The biology of interleukin-6. Blood, 74:1-10.

Maltais F, Simard AA, Simard C, et al. 1996. Oxydative capacity of the skeletal muscle and lactic acid kinetics during exercise in normal subjects and in patients with COPD. Am J Respir Crit Care Med, 153:288-93.

Pauwels RA, Buist S, Calverley PM, et al. 2001. GOLD Scientific Committee. Global strategy for the diagnosis, management, and prevention of chronic obstructive pulmonary disease. NHLBI/WHO Global Initiative for Chronic Obstructive Lung Disease (GOLD) Workshop summary. Am J Respir Crit Care Med, 163:1256-76.

Pinto-Plata VM, Müllerova H, Toso JF, et al. 2006. C-reactive protein in patients with COPD, control smokers and non-smokers. Thorax, 6:23-8.

Quanjer PH, Tammeling GJ, Cotes JE, et al. 1993. Standardized lung function testing. Eur Respir J, 6:5-40.

Ringsted C, Eliasen K, Gothgen IH, et al. 1990. Positive correlation between 'the arterial oxygen extraction tension' and mixed venous $\mathrm{PaO}_{2}$ but lack of correlation between 'the oxygen compensation factor' and cardiac output in 38 patients. Scand J Clin Lab Invest Suppl, 203:67-73.

Sauleda J, Garcia-Palmer F, Wiesner RJ, et al. 1998. Cytochrome oxidase activity and mitochondrial gene expression in skeletal muscle of patients with chronic obstructive pulmonary disease. Am J Respir Crit Care Med, 157(5 Pt 1):1413-7.

Schols AM, Buurma WA, Staal van den Brekel AJ, et al. 1996. Evidence for a relation between metabolic derangements and increased levels of inflammatory mediators in a subgroup of patients with chronic obstructive pulmonary disease. Thorax, 51:819-24.

Semenza GL. 2000. HIF-1 factor: mediator of physiological and pathophysiological responses to hypoxia. J Appl Physiol, $88: 1474-80$

Siggard-Andersen M, Siggard-Andersen O. 1990. The Oxygen status algorithm: a computer program for calculating and displaying $\mathrm{pH}$, blood gas data. Scand J Clin Lab Invest, 59(Suppl 203):29-45.

Siggaard-Andersen O, Wimberley PD, Gøthgen IH, et al. 1984. A mathematical model of the hemoglobin-oxygen dissociation curve of human blood and of the oxygen partial pressure as a function of temperature. Clin Chem, 30:1646-51

Siggard-Andersen O, Fogh-Andersen N, Gøthgen IH, et al. 1995. Oxygen status of arterial and mixed venous blood. Crit Care Med, 23:1284-93.

Takabatake N, Nakamura H, Abe S, et al. 2000. The relationship between chronic hypoxemia and activation of the tumor necrosis factor- $\alpha$ system in patients with chronic obstructive pulmonary disease. Am J Rev Crit Care Med, 161:1179-84. 
Wouters EFM. 2005. Local and systemic inflammation in chronic obstructive pulmonary disease. Proc Am Thorac Soc, 2:26-33.

Yokoe T, Minoguchi K, Matsuo H, et al. 2003. Elevated levels of C-reactive protein and interleukin- 6 in patients with obstructive sleep apnea syndrome are decreased by nasal continuous positive airway pressure. Circulation, 107:1129-34.
Yu AY, Frid MG, Shimoda LA, et al. 1998. Temporal, spatial and oxygen-regulated expression of hypoxia-inducible factor-1 in the lung. Am J Physiol Lung Cell Mol Physiol, 275:L818-L26. 
